\title{
1. The regulation of social media influencers: an introduction
}

\section{Catalina Goanta and Sofia Ranchordás}

\section{SETTING THE SCENE}

Nikkie de Jager was an unknown teenager from the small Dutch town of Uden until one of her videos ('The Power of Make-Up') went 'viral', amassing in a short period of time nearly 40 million views. ${ }^{1} \mathrm{Her}$ 'NikkieTutorials' make-up channel on YouTube soon became an online sensation with millions of views from different countries, helping her build an international reputation as a 'YouTuber' and make-up artist. Without prior training in communication, advertising, or even the beauty sector, de Jager's is a good example of an emerging 'profession': 'social media influencer'. A growing number of individuals, often without any traditional professional certification, have a job which consists in sharing moments of their daily lives, offering advice in different areas (e.g., fitness, beauty, food), and while doing so, endorsing consumer goods and services. In many cases, these social media influencers fail to properly disclose the commercial nature of their relationship with the companies behind these advertisements. Moreover, these channels are not limited to lifestyle advice and can have broader societal consequences, for example, on election results. The comedy and commentary channel of German YouTuber Rezo is a good example of how social media influencers are also having an impact in politics. On 18 May 2019, Rezo published a video criticizing the German Christian Democratic Union party (CDU), which gained well over 15 million views in three months, ${ }^{2}$ and was subsequently endorsed by at least 90 other YouTubers, in an attempt to hold German politicians responsible, especially for their perceived lack of commitment to the fight against global

1 NikkieTutorials, YouTube channel (YouTube, 2015) https://www.youtube.com/ watch? $\mathrm{v}=\mathrm{a} 40 \mathrm{v} 8 \mathrm{qvZ2}$ _w\&t=266s. All sources in this chapter last accessed 7 March 2020.

2 Rezo, YouTube channel (YouTube, 2019) https://www.youtube.com/watch?v= 4Y11ZQsyuSQ. 
warming. While the evidence behind many of his statements and their underlying motivation could be discussed, the reputational damage to CDU was far from negligible.

In a world where YouTube and Instagram have become the new television, and where children and teenagers closely follow the advice given by social media celebrities and aspire to become influencers rather than doctors, firemen or astronauts, it is imperative to discuss the need to regulate this activity.

The emergence of social media influencers fits within the broader framework of peer-to-peer services, the sharing economy, the 'gig economy' and the 'do-it-yourself trend' that has grown dramatically in the past decade. ${ }^{3}$ While peer-to-peer networks and social media have received a great deal of attention from academia throughout the whole spectrum of social sciences, the same cannot be said about social media influencers. ${ }^{4}$ However, this phenomenon is generating a wealth of new legal and ethical issues which deserve to be addressed. For example, how should the advertising practices of influencers be regulated? Should these individuals be treated as professionals or as consumers? How should their speech be regulated? Is influencer marketing a new type of work? What is the role of online platforms? Thus far, these issues have been widely discussed in the media and have attracted the attention of watch

3 See for instance Vanessa Katz, 'Regulating the Sharing Economy' (2015) 30 Berkeley Tech. L.J. 1067; Erez Aloni, 'Pluralizing the Sharing Economy' (2016) 91 Wash. L. Rev. 1397; Alessio Di Amato, 'Uber and the Sharing Economy' (2016) 2 Italian L.J. 177; Stephen R Miller, 'First Principles for Regulating the Sharing Economy' (2016) 53 Harv. J. on Legis. 147; Jacob Galley, 'Awareness and Usage of the Sharing Economy' (2016) 139 Monthly Lab. Rev. 1; Inara Scott and Elizabeth Brown, 'Redefining and Regulating the New Sharing Economy', 19 U. Pa. J. Bus. L. 553 (2016-2017); Sofia Ranchordás, 'The Risks and Opportunities of the Sharing Economy’ (2016) 7(4) European Journal of Risk Regulation 650; Sofia Ranchordás, 'Does Sharing Mean Caring: Regulating Innovation in the Sharing Economy' (2015) 16 Minn. J.L. Sci. \& Tech. 413; Megan Carboni, 'A New Class of Worker for the Sharing Economy' (2015-2016) 22 Rich. J.L. \& Tech. 1; Andrew G Malik, 'Worker Classification and the Gig-Economy' (2016-2017) 69 Rutgers U.L. Rev. 1729.

4 See for instance Cass R Sunstein, \#Republic: Divided Democracy in the Age of Social Media (Princeton University Press 2017); Jack M Balkin, 'Digital Speech and Democratic Culture: A Theory of Freedom of Expression for the Information Society' (2004) 79(1) New York University Law Review 1. See also Nathanael J Mitchell, 'Judge 2.0: A New Approach to Judicial Ethics in the Age of Social Media' (2012) Utah L. Rev. 2127; Cathryn Rudolph, 'Unleashing Law Reviews onto Social Media: Preventing Mishaps with a Social-Media Policy’ (2013) 30 T. M. Cooley L. Rev. 187; Kathleen McGarvey Hidy, 'Business Disputes over Social Media Accounts: Legal Rights, Judicial Rationales, and the Resultant Business Risks' (2018) Colum. Bus. L. Rev. 426; Jennifer K Gregory, '\#BewareofOvershare: Social Media Discovery and Importance in Intellectual Property Litigation' (2012-2013) 12 J. Marshall Rev. Intell. Prop. L. [i]. 
dog organizations such as the United States (US) Federal Trade Commission and the Italian Competition Authority, which have been attentive to the topic of hidden advertising. In 2018, the Federal Trade Commission reminded 90 influencers that they should disclose any 'material connection' with advertised consumer goods, underlining that truth in advertising also applies to social media. As a result, recent US literature has attempted to explore the legal standard applicable to advertising by influencers. ${ }^{5}$ Additional literature on European regulatory frameworks such as the Unfair Commercial Practices Directive has been emerging in the past year. ${ }^{6}$ Other disciplines, such as marketing, started devoting attention to the influencer phenomenon earlier, ${ }^{7}$ or have already deployed methodologies that allowed for quantitative analyses,

5 In August 2019, a HeinOnline search of the Law Journal Library revealed 28 articles, which mostly deal with influencers and advertising. See Laura E Bladow, 'Worth the Click: Why Greater FTC Enforcement Is Needed to Curtail Deceptive Practices in Influencer Marketing' (2018) 59(3) William \& Mary Law Review 1123; Gonenc Gurkaynak, C Olgu Kama and Burcu Egun, 'Navigating the Uncharted Risks of Covert Advertising in Influencer Marketing' (2018) 39(1) Business Law Review 17; Aimee Khuong, 'Complying with the Federal Trade Commission's Disclosure Requirements: What Companies Need to Know When Using Social-Media Platforms as Marketing and Advertising Spaces' (2016) 13(1) Hastings Business Law Journal 129; Benjamin Edelman and Wesley Brandi, 'Risk, Information, and Incentives in Online Affiliate Marketing' (2015) 52 J. Marketing Res. 1; Leah W Feinman, 'Celebrity Endorsements in Non-Traditional Advertising: How the FTC Regulations Fail to Keep Up with the Kardashians' (2011) 22 Fordham Intell. Prop. Media \& Ent. L.J. 97, 137-42; Sarah Arayess and Dominique Geerts, 'Social Media Advertising: How to Engage and Comply' (2017) Eur. Food \& Feed L. Rev. 529; Michael R Justus, 'The Laws of Influence' (2016) 32(3) Communications Lawyer, 25; Rahmon Brown, 'Was That an Ad' (2016) 29 Loy. Consumer L. Rev. 225; Amy Ralph Mudge, 'Native Advertising, Influencers, and Endorsements: Where Is the Line between Integrated Content and Deceptively Formatted Advertising' (2017) 31(3) Antitrust 80; Angela J Campbell, 'Rethinking Children's Advertising Policies for the Digital Age' (2016) 29 Loy. Consumer L. Rev. 1; Meryl Bernstein, 'How to Avoid the FTC Not Liking Your Next Campaign' (2016) 262 Managing Intell. Prop. 49; Mark Goodrich and Jason Howell, 'Influencers: What Every Brand and Legal Counsel Should Know' (2018) 11(1) Landslide 15; Caroline E Kim, 'Insta-Fringement: What Is a Fair Use on Social Media' (2018) 18(1) John Marshall Review of Intellectual Property Law [ix].

6 Jan Trzaskowski, "Identifying the Commercial Nature of "Influencer Marketing" on the Internet' (2018) 65 Scandinavian Studies in Law 81; Christine Riefa and Laura Clausen, 'Towards Fairness in Digital Influencers' Marketing Practices' (2019) 8 Journal of European Consumer and Market Law 64; Sophie C Boerman, Natali Helberger, Guda van Noort and Chris J Hoofnagle, 'Sponsored Blog Content: What Do the Regulations Say: And What Do Bloggers Say’ (2018) 9(2) Journal of Intellectual Property, Information Technology and Electronic Commerce Law 146.

7 See (infra n 10). 
such was the case of computer science. ${ }^{8}$ Law still has a long way to go as the relevance of social media influencers remains heavily underestimated.

In this introductory chapter, we delve into the concept of 'influencer', we explain how influencer marketing operates from a legal perspective, and provide an overview of the most pregnant legal and ethical issues. This chapter shows that influencer marketing is gaining increasing importance not only in the field of advertising and consumer law but also in the context of the protection of children against negative role models on social media, the assessment of the limits of free speech in the digital age, and the need to design novel methodologies to conduct empirical and interdisciplinary research on social media. Although influencer marketing may seem 'child's play' to many lawyers who prefer to be disconnected from social media, the truth is that this type of content monetization is a billion-euro business, not only for companies but also for social media influencers. We conclude this chapter with a roadmap of this book's contribution to existing literature.

\section{SOCIAL MEDIA INFLUENCERS: A DEFINITION}

Influencer marketing has existed for decades and until recently consisted in hiring individuals with a significant social impact (e.g., journalists with well-read restaurant newspaper columns or celebrities) to advertise products in a genuine way. The emergence of social media networks has however profoundly changed the way in which marketing information is used to promote products and boost, shape or create new consumer demand. Modern influencer marketing relies on 'social media influencers', a recent social media phenomenon which reflects endorsement practices by individuals with a significant social media audience, with the purpose of increasing online engagement for the endorsed product or service. The Word of Mouth Marketing Association defines influencer marketing as: "the act of a marketer identifying and engaging influencers to share information with influencees in pursuit of a business goal'. 9 At its core, modern influencer marketing is a digital form of word-of-mouth ('WOM') advertising, a well-known effective marketing technique which relies on the endorsement of information by trusted individuals

8 Arunesh Mathur, Arvind Narayanan and Marshini Chetty, 'An Empirical Study of Affiliate Marketing Disclosures on YouTube and Pinterest' (Arxiv, 17 January 2019) https://arxiv.org/abs/1901.05949.

9 WOMMA, 'The WOMMA Guide to Influencer Marketing' (WOMMA, 2017) https://www.ana.net/content/show/id/womma, at 7. See also Marlis Jahnke, 'Ist Influencer Marketing Wirklich Neu', in Marlis Jahnke (ed), Influencer Marketing: Für Unternehmen und Influencer: Strategien, Plattformen, Instrumente, rechtlicher Rahmen (Springer 2018) at 4. 
within small communities or networks built on the basis of mutual trust and repeated interactions. Individuals who offer WOM typically have reputational incentives to keep providing correct information. With the development of the Internet, electronic Word-of-Mouth (eWoM) has started serving similar purposes, converting online communities into spaces of trust. ${ }^{10}$

Social media influencers play the role of a trusted individual in the online community in a certain way; they are trusted because they present themselves as authentic, approachable and relatable individuals. ${ }^{11}$ With the growing traffic of YouTube videos and Instagram accounts, companies quickly identified

10 For the classical word-of-mouth advertising, see Emanuel Rosen, The Anatomy of Buzz (Harper Collins Business 2000); Frank M Bass, 'A New Product Growth for Model Consumer Durables’ (1969) 15(5) Manag. Sci. 215; Dee T Allsop, Bryce R Bassett and James A Hoskins, 'Word-of-Mouth Research: Principles and Applications' (2007) 47 (4) J. Adv. Res. 398; Ernest Dichter, 'How Word-of-Mouth Advertising Works' (1966) 44 (6) Harv. Bus. Rev. 147; David Godes and Dina Mayzlin, 'Using Online Conversations to Study Word-of-Mouth Communication' (2004) 23(4) Mark. Sci. 545; Jonathan Frenzen and Kent Nakamoto, 'Structure, Cooperation, and the Flow of Market Information' (1993) 20(3) J. Consum. Res. 360. For autonomous or eWOM, see Wendy W Moe and Michael Trusov, 'The value of social dynamics in online product ratings forums' (2011) 48(3) Journal of Marketing Research 444; Fouad El Ouardighi, Gustav Feichtinger, Dieter Grass, Richard Hartl and Peter M Kort, "Autonomous and Advertising-Dependent "Word of Mouth" under Costly Dynamic Pricing' (2016) 251(3) European Journal of Operational Research 860; Vera Blazevic, Wafa Hammedi, Ina Garnefeld, Roland T Rust, Timothy Keiningham, Tor W Andreassen, Naveen Donthu and Walter Carl, 'Beyond Traditional Word-of-Mouth: An Expanded Model of Customer Influence’ (2013) 24(3) Journal of Service Management 294; Tor W Andreassen and Sandra Streukens, 'Service Innovation and Electronic Word-of-Mouth: Is It Worth Listening To?' (2009) 19(3) Managing Service Quality 249; Mira Lee and Seounmi Youn, 'Electronic Word of Mouth (eWOM)' (2009) 28(3) International Journal of Advertising 473; Vasant Dhar and Elaine A Chang, 'Does Chatter Matter? The Impact of User-Generated Content on Music Sales' (2009) 23(4) Journal of Interactive Marketing 300; Paul Dwyer, 'Measuring the Value of Electronic Word of Mouth and its Impact in Consumer Communities' (2007) 21(2) Journal of Interactive Marketing 63; Greg Nyilasy, 'Word of Mouth - What We Really Know - And What We Don't' in Justin Kirby and Paul Marsden (eds), Connected Marketing (Butterworth-Heinemann 2005) at 161; Fred D Reynolds and William R Darden, 'Mutually Adaptive Effects of Interpersonal Communication' (1971) 8(4) Journal of Marketing Research 449; Robert V Kozinets, Kristine de Valck, Andrea C Wojnicki and Sarah JS Wilner, 'Networked Narratives: Understanding Word-of-Mouth Marketing in Online Communities' (2010) 74(2) Journal of Marketing 71; Yi-Cheng $\mathrm{Ku}$, Chih-Ping Wei and Han-Wei Hsial, 'To Whom Should I Listen? Finding Reputable Reviewers in Opinion Sharing Communities' (2012) 53(3) Decision Support Systems 534; Jie Feng and Purushottam Papatla, 'Advertising: Stimulant or Suppressant of Online Word of Mouth?' (2011) 25(2) Journal of Interactive Marketing 75.

11 Geometry Global, 'The Influence of Influencers' (Geometry Global, June 2017) https://drive.google.com/file/d/0B8uin-AAtdr-bER6ZVdyMjkxblk/view, at 13. 
a novel instrument to promote their products and expand their marketing strategy. Companies started reaching out to influencers (or being approached by them), and since 2015 influencers have become important actors in shaping what users trust and consume. ${ }^{12}$

One of the challenges of influencer marketing in the digital age is precisely its definition. Influencer marketing is characterized by diversity at several levels: social media influencers share common features such as their reliance on social media networks, the production of regular media content, and a peer-to-peer engagement with the public on apparently non-commercial grounds (e.g., sharing workouts on YouTube to inspire users rather than to offer services). Nevertheless, since social media influencers engage with different audiences and focus on different types of content, these general features are insufficient to truly understand their nature. In other words, social media influencers should be primarily characterized by reference to a number of specific elements. These features may be crucial to assess whether an individual can be considered as an influencer or not.

The first element is the industry where an influencer operates. In 2017, Forbes tracked top influencers from 12 categories: pets, parenting, fashion, entertainment, travel, gaming, fitness, beauty, home, food, tech \& business, and kids. ${ }^{13}$ On the basis of this analysis, the top 10 influencer pets (e.g., Grumpy Cat, Nala) had at that moment a total reach of 68 million users. In comparison, the gaming sector does much better at amassing followers (e.g. the highest outreach in this sector was 228 million users). The same applies to the beauty industry which at the time of the Forbes analysis has about 135 million followers. The total dimension of the industry is relevant as the qualification of an individual's influence will be evaluated according to the number of followers in the industry in which he or she operates. In the gaming sector, influencers will thus need to have several hundreds of thousands of followers to become relevant, while in more niche markets some thousands will be sufficient to have an impact on the market.

Most influencers will be active in a specific sector as they wish to give the impression that they are loyal to a fan base interested in this sector. However, several influencers try to branch out into multiple fields, to diversify their content and gain new followers. ${ }^{14}$ Not surprisingly, the sectors listed by Forbes

12 Celie O'Neil-Hart and Howard Blumenstein, 'Why YouTube Stars Are More Influential than Traditional Celebrities' (ThinkwithGoogle, July 2016) https://www .thinkwithgoogle.com/consumer-insights/youtube-stars-influence/.

13 Forbes, 'Top Influencers' (Forbes, 2017) https://www.forbes.com/top -influencers/\#2ed2b38a72dd.

14 See for instance PewDiePie. The most famous gaming YouTuber in the world successfully started making commentary videos where he reacts to conflicts between 
where influencers are active are retail-friendly and prone to the monetization of influence. Given the large amount of competitors on these markets, the use of influencers may be crucial to attract the attention of consumers. However, there are some influencers who do not fit into predefined market definitions. Lil Tay, for example, is a nine-year-old Canadian influencer who rose to fame in February 2018 by claiming to be the 'youngest flexer of the century'. ${ }^{15}$ The profane pre-teen who is not even officially allowed to have her own Instagram account would post videos of herself in luxurious homes and cars, throwing money and boasting about her wealth to create controversy. This image was further fuelled by content involving other social media figures, including footage of physical fights and smoking. This strategy resulted in a gain of 2.5 million followers on Instagram between February and June 2018. ${ }^{16}$ This influencer did not operate in a specific market, instead she monetized controversy and outrage for the entertainment of her followers, hoping to attract sponsorships from different industries, or launching other business ventures on the basis of this popularity. In the meantime, her content was removed from YouTube and Instagram, but this type of outrageous content as a novel business model to attract followers continues to thrive. While this model may not attract the best commercial deals in the children's sector (no children's company would like to be affiliated with a smoking nine-year-old), it attracts the initial attention that some influencers may need to start up their own businesses (e.g., merchandise) or additional careers (e.g., music, acting).

The second feature of an influencer brand is the source of their popularity. Here we can distinguish between celebrities who became famous outside social media, but use social media for their personal and professional promotion, and influencers who are exclusively known for their activity on social media. The first category includes well-known singers, football players, actors, reality TV stars (e.g., Kim Kardashian), and professional fashion models. ${ }^{17}$

influencers. He also hosts a famous 'meme review', whereby he reacts to humorous images made by his fans and left in a designated Reddit thread, PewdiepieSubmissions, Reddit thread (Reddit, 2019) https://www.reddit.com/r/PewdiepieSubmissions.

15 'Flexer' is a rap slang term for 'showing off, gloating, or boasting', see Ehak Anwar, "What Does "Flex" Mean in Slang? Or, Why Both "No Flex Zones" and "Flex Friendly Zones" Are Necessary' (Bustle, 12 May 2015) https:/www.bustle.com/ articles/82669-what-does-flex-mean-in-slang-or-why-both-no-flex-zones-and-flex -friendly-zones.

16 Taylor Lorenz, 'The Lil Tay Saga Reaches Its Logical Conclusion' (The Atlantic, 24 May 2018) https://www.theatlantic.com/technology/archive/2018/05/the-lil-tay -saga-reaches-its-logical-conclusion/561116/.

17 Lori Keong and Rachel Epstein, 'The Top 10 Most-Followed Celebrities on Instagram in 2019' (Marie Claire, 24 July 2019) https://www.marieclaire.com/ celebrity/a23863/most-followed-celebrities-on-instagram-in-2016/. 
The second category refers to individuals who were fully anonymous before they started attracting attention on social media and owe their popularity to YouTube, Instagram or personal blogs (e.g., NikkiTutorials). This second element is important as the first group (showbusiness professionals in general) ought to be well informed as to their role as public figures and the compulsory disclosure of sponsorship. The second group (originally 'peers'), on the contrary, may start being treated in the same way as the first one (the "professionals') only from the moment they start amassing a significant amount of market power and influence, typically translated into the number of followers and the ability to shape for example their commercial behaviour.

The third element that can help us characterize an influencer is their influence analytics, that is, any data-driven measurement of how far their influence spreads (e.g. the number of followers, subscribers, views, likes and dislikes, retweets, impressions). These metrics point to which influencers are well known - and have managed to amass the highest number of followers in a specific industry - and those influencers with a more limited impact on the market. Forbes acknowledged top 10 mega-influencers in each of the 12 industries mentioned above, as this category of influencers (e.g. those with tens of millions of followers) had gotten a lot of traction. Since then, not only are brands focused on smaller influencers who can create more genuine content, but the number of content creators has also been on the rise. Simple YouTube searches in any of these industries will now reveal a wider spectrum of smaller, less well-known influencers who rely on social media for a living, such as Jimmy Broadbend, who owns a YouTube channel with over 100,000 subscribers, around 1,500 of whom watch him play live racing simulations every day. ${ }^{18}$ With his analytics, Broadbend would most likely qualify as a 'micro-influencer'. In addition, the advertising industry also recognizes so-called 'nano-influencers', who have a considerably smaller follower base (e.g., even thousands of followers), but who are thought to be perceived of as more sincere, and thus be able to engage their audience more powerfully. ${ }^{19}$

Some of these analytics, such as reach or impressions, entail the number of unique people who see given content, and namely the delivery of content to someone's feed. The impact of the influencer is important not only to determine whether someone is indeed a true influencer but also to define their

18 Richard Priday, 'YouTube's Algorithm Is Causing Havoc for Gaming Livestreamers' (Wired, 16 May 2018) http://www.wired.co.uk/article/youtube -streaming-content-id-ban-algorithm.

19 Richard Godwin, 'The Rise of the Nano-Influencer: How Brands Are Turning to Common People' (The Guardian, 14 November 2019) https://www.theguardian .com/commentisfree/2018/nov/14/rise-nano-influencer-brands-celebrities-youtube -instagram. 
value as an advertiser. When approaching an influencer for the promotion of a product, the advertising industry may either make payment dependent on the size of the influencer (e.g., number of followers) or on more granular, post-oriented statistics (e.g., number of views), which influencers are often asked to report on as part of their influencer agreement. ${ }^{20}$ Platforms like Social Blade are often used to gauge the activities of influencers on different social media, as well as to track their channel or profile analytics in real time. ${ }^{21}$

The fourth feature of an influencer is their legal status, closely linked to the pursued business models. Here we can distinguish between influencers who have companies, influencers who have the legal status of a freelancer, and influencers who are still consumers themselves. This is a very important legal aspect, which is very rarely obvious to users. Some high-earning influencers launch their own brand of products and create companies to this end. Other influencers - also depending on the industry - will rely on freelance legal forms to gather financial resources through platforms such as Patreon. Lastly, influencers who are still consumers may be involved in influencer marketing, but with more limited ways of earning financial benefits.

In conclusion, it is difficult to determine whether an individual with a large number of followers is indeed an influencer or not, and if so, what kind of influencer they are. The type of industry this person appears to operate in (or produce content about), the source of their social media popularity, a very significant number of followers/content views - to be assessed by comparison to what the norm is in a certain industry - and the existence of a business underlying the influencer's operation are good rules of thumb that capture the functioning of influencer marketing. However, as the following section explains, the most important aspect of modern influencer marketing remains the ability for content creators to monetize content on social media.

\section{LEGAL QUALIFICATION OF CONTENT MONETIZATION}

Influencer marketing conveys the appearance of a 'peer-to-peer' or grassroots form of content production where average individuals who have reached fame and fortune through their authentic and engaging content endorse products they genuinely use and services they believe in. This peer-to-peer suggestion does not even scratch the surface of what influencer marketing is truly about: monetization through advertising on social media. In a nutshell, monetization entails creating revenue out of content posted on social media by creators.

20 See Chapter 12

21 Social Blade Analytics (Social Blade, 2019) https://socialblade.com. 
Using YouTube, Instagram, Facebook and blogs for marketing purposes is, nonetheless, a tricky business as brands have a difficult time measuring what social media engagement actually means for their brand.

In this section, we cluster the different marketing activities which are possible on social media according to four business models. These business models highlight the transactions and stakeholders influencers engage in and with for the purpose of monetizing their content.

The first business model used by influencers is affiliate marketing, 'an endorsement marketing strategy that pays affiliates (the content publishers) money when users click on their customized URLs'. ${ }^{22}$ The main feature of affiliate marketing is that influencers are paid for sales/clicks. An example of this business model is any Instagram post which includes a discount code. When such a code is included, the influencer will typically receive a commission for every item purchased with it. Although the practices of affiliate marketing are not fully transparent, we can assume that this can either be (i) a service contract between either a producing/selling company and the influencer, or as the case may be, between an advertiser and the influencer; or (ii) an innominate contract which can bear any name (including names which circulate on different template websites such as 'Influencer Marketing Campaign Contract', 'Influencer Marketing Contract', etc.), and which will establish advertising obligations on the influencer, as well as payment obligations on the advertiser/seller/service provider. Once more, it is impossible to determine, on the basis of publicly available information, whether such contracts are concluded with companies or with individuals, as the stakeholders of these activities are becoming more and more complicated to map. For instance, high-earning influencers will be managed by their own companies (e.g., Chiara Ferragni is managed by her company, The Blonde Salad), whereas smaller-scale influencers might use the services of an agency which can also represent them in contracts with advertisers, as they may do with tens of other influencers. In this business model, affiliate marketing takes the shape of product placement, review or promotion, under the established contractual conditions.

The second business model is the exchange of goods and/or services. In this case, the advertising brand offers its goods or services for a post, a review, a mention and/or a story made by the influencer on their social media, depending on the nature of the industry. This seems to be a very popular form of influencer marketing, and can be initiated by the brand (e.g., Disney reaching out to influencers and taking them to a specific Disneyland location for an event), or by the influencer (e.g., micro-influencers who reach out to hotels to get free stays). This agreement can be explicit, if the offer and acceptance model is ful-

22 Mathur et al. (supra n 8 ). 
filled in a more formal way (e.g., by signing a contract), or it can be implicit, if the influencer accepts, through their conduct, that they will promote the goods/ services in a way that the other party can benefit from, based on negotiations undertaken in the private messaging of social media platforms.

The third business model is that of endorsement deals. These are framework contracts by which influencers receive compensation for advertising as indicated by the brand. A good example in this respect is Luka Sabbat's contract with Snap Inc. ${ }^{23}$ In 2018, Sabbat, a fashion/lifestyle influencer who was supposed to advertise eyewear made by social media company Snapchat, was sued by the company's PR agency for non-performance. So far, the litigation has further revealed the conditions of the contract, which Sabbat had broken: a lump sum paid in exchange for a number of posts and stories on Instagram. ${ }^{24}$ In such a transaction, the influencer acts more or less like a brand ambassador, and often is limited by exclusivity clauses, meaning that they will have to specifically not endorse any competing brands.

The fourth business model reflects more complex business operations, which include the influencer becoming a producer/provider of goods or services themselves, or - depending on how the agreement is built - collaborating with other companies for guest products. This is the so-called 'merch' category, namely branded merchandise which followers will buy from the influencer to show their support. Branded merchandise in this case can take many forms. Several influencers create their own brands of products once they have established themselves on a certain market. This is for example the case of beauty influencer Jeffrey Star who launched his own make-up brand Jeffree Star Cosmetics. His YouTube channel heavily features this brand identity, and he constantly features his own products also on Instagram or Snapchat. PewDiePie is one of the mega-influencers who did not launch his own brand, but preferred to collaborate with a company (Clutch Chairz) and launch a product branded with his name. ${ }^{25}$ In the beauty industry, this practice is very popular, with influencers lending their names to different products launched by established companies. This business model raises a number of legal questions

23 Alexandra Ma, '20-Year-Old "Influencer" Sued for Allegedly Refusing to Wear Snap Spectacles in Public Despite Being Paid \$45,000' (Business Insider, 1 November 2018) https://www.businessinsider.com/influencer-luka-sabbat-sued-for -alleged-refusal-to-wear-snap-glasses-2018-11.

24 See Chapter 9.

25 Clutch Chairz, 'Pewdiepie Clutch Gaming Chair' (Clutch Chairz, 2019) https:// usa.clutchchairz.com/product/pewdiepie-edition-throttle-series/. Pewdiepie still sells his own branded merchandise (e.g., apparel branded with the characters he creates in the games he streams online) through an intermediary, although it is unclear who the producer of the goods is. See Represent, 'Pewdiepie Store' (Represent, 2019) https:// represent.com/store/pewdiepie. 
as once again the legal obligations of the influencers are determined by their agreement with the parties whose products they promote. In the case of an influencer owning a brand and promoting it among other brands, it is unclear what capacity the influencer acts in - as the CEO of the company, as an advertiser of the company, or as an actor completely independent from the company. The same can be said for co-created products, especially if these products are included in the normal review activity of an influencer, which raises a lot of ethical questions relating to conflicts of interests - will an influencer ever say something negative about their own products?

The four business models identified above are all based on the influencer marketing of goods and services, namely using the influencer figure in advertising itself, and obtaining financial contributions from brands or PR agencies, as well as from their own companies. In addition, content creators can make money by engaging with platforms or directly with viewers, albeit not through promoting goods and services. The first case is that of the well-known Google-owned AdSense programme, allowing ads to be displayed during YouTube videos. In the second case, influencers may choose to generate revenue with their content by using crowdfund-like platforms such as Patreon, where they can ask fans for financial subscriptions to unlock original content created by the influencer, who does not have to advertise any products. Platforms such as YouNow even gamify financial contributions: a broadcaster's audience may purchase so-called 'bars' using real money, and this token can be used to give 'gifts' to a given streamer. In turn, the streamer can convert the gifts back into real money. ${ }^{26}$

\section{BEYOND ADVERTISEMENT LAW QUESTIONS}

Based on the literature available on influencers so far, marketing has taken a prominent role, leading to questions on how influencers should disclose paid endorsements and sponsorships. However, other equally important issues remain unexplored. Influencers pose challenges that have remained overlooked by the literature as many Internet users that are not interested in typical influencer content (beauty, fashion, fitness, politics) may not easily recognize these problems. This happens because social media content is a bubble of its own, and established media (e.g., TV and online newspapers) only follow a selection of scandals relating to content creation, such as influencers asking for free hotel rooms, ${ }^{27}$ or not disclosing ads on Instagram regarding for

26 YouNow, 'Partners' (YouNow, 2019) https://www.younow.com/partners.

27 Chelsea Ritschel, 'Luxury Dublin Hotel Bans All Social Media Influencers' (The Independent, 18 January 2018) https://www.independent.co.uk/life-style/hotel-bans 
example the Fyre Festival. ${ }^{28}$ It therefore comes as no surprise that academics, law-makers, judges or even the average consumer might not be as familiar with serious incidents such as: (i) Tanacon, a failed festival organized by influencer Tana Mongeau, which, due to negligent organization, caused health issues in the form of sunburns and financial losses to thousands of teenagers queuing in the Californian sun to see their favourite YouTuber; ${ }^{29}$ (ii) the endorsement by influencers such as Gabbie Hanna of fraudulent business models of dubious companies who scam consumers by offering luxury products for free, when in fact the business would make profits out of buying such products from Aliexpress, dropshipping them to consumers, and charging high transportation costs $;{ }^{30}$ (iii) the concept of an 'influencer incubator' promoted by Jake Paul, who built his own influencer team to allegedly teach and generate content together with his so-called Team 10 , of which he is formally the manager; ${ }^{31}$ or (iv) constant scandals between friends with competing business interests, such as beauty gurus Tati and James Charles, who made videos supposedly aimed at explaining their feelings about a personal conflict between them, but which they used to criticize each other's brands, products, or, to the contrary, to promote their own, and doing so for potentially hidden commercial reasons. ${ }^{32}$

These are only a few examples of the everyday realities of content creation on social media: it is an industry maturing at skyrocketing speed, where new business opportunities are created regularly. These opportunities challenge the boundary between what is real and what is fake: CGI influencers, illustrated influencers, influencers who do not have a professional stance on conflicts of interests, or who rely on pranks (and therefore faking reality) to create shock value and get views, impressions and likes. The four illustrations provided

-influencers-instagram-social-media-stars-elle-darby-the-white-moose-cafe-a8166926 .html.

28 Catalina Goanta, 'Consumers on Fyre: Influencer Marketing and Recent Reactions of the United States Federal Trade Commission' (2017) 3 Transatlantic Antitrust and IPR Developments 35.

29 Megan Farokhmanesh, 'YouTuber's Anti-VidCon Convention TanaCon Was Such a Disaster that Fans Are Comparing It to Fyre Fest' (The Verge, 26 June 2018) https://www.theverge.com/2018/6/26/17500590/tanacon-disaster-fyre-fest-tana -mongeau-youtuber.

30 Will Sommer, 'Instagram Influencers Dupe their Fans with "Free” Products' (The Daily Beast, 14 January 2019) https://www.thedailybeast.com/instagram-influencers -dupe-their-fans-with-free-products.

31 Jonathan Shieber, 'Social Media Star Jake Paul Raises \$1 Million to Become a Social Media Mogul' (TechCrunch, 17 January 2017) https://techcrunch.com/2017/ 01/17/social-media-star-jake-paul-raises-1-million-to-become-a-social-media-mogul/.

32 Alex Abad-Santos, 'James Charles, Tati Westbrook, and the Feud that's Ripping Apart YouTube's Beauty Community' (Vox, 18 May 2019) https://www.vox.com/ 2019/5/16/18617895/james-charles-tati-westbrook-feud-drama-3-million-subscribers. 
above translate into a wide range of legal issues, including consumer fraud, employment issues, or unfair commercial practices.

In particular, defective performance or non-performance may give rise to contractual remedies that may be demanded by the parents of children who spent thousands of dollars to travel across the US without having the opportunity to see their YouTube idol.

Moreover, if influencers are to be qualified as professionals in the world of social media, it could be argued that promoting dubious businesses without any due diligence on the legitimacy of a product or service, as well as not recognizing conflicts of interests, could raise ethical issues. Similarly, the relationship between a group of influencers and their manager who gives them instructions on what should be posted online, when, and what it should look like, has the makings of an employment relationship, and is very much reminiscent of earlier discussions on Uber drivers being employees. ${ }^{33}$ These are examples of legal issues reflected in the book, with the view of broadening the narrative around influencer marketing. These legal issues deserve thorough analysis as visual content and advertising are increasingly moving from traditional channels (e.g., television, newspapers, magazines) to social media. As this occurs, influencer marketing will continue to grow and there is the risk that many influencers will compete for a steady audience using unethical practices that we are already beginning to see today (e.g., making defamation an acceptable practice to draw the attention of fluctuating audiences, cause outrage or play with users' tendency to prefer pictures of children in advertising by introducing children at an early age to the world of influencer marketing).

Most importantly, influencers may soon influence how citizens vote in elections. Rezo, the German YouTuber mentioned above, is by no means the first content creator who has spoken out about politics. Barack Obama and Joe Biden are just two examples of established politicians who have been trying to engage creators in campaigns relating to social responsibility. ${ }^{34}$ Yet, influencers may also become politicians themselves. Kim Kataguiri, the Brazilian YouTuber with over half a million subscribers, is an illustration of the ability to leverage social media power during elections. Kataguiri became a member of the Brazilian Parliament in autumn 2018, and is currently creat-

33 See for instance Valerio De Stefano, 'The Rise of the Just-in-Time Workforce: On-Demand Work, Crowdwork, and Labor Protection in the Gig-Economy' (2016) 37 Comp Lab L \& Pol'y J 471; Jeremias Prassl and Martin Risak, 'Uber, Taskrabbit, and Co.: Platforms as Employers - Rethinking the Legal Analysis of Crowdwork' (2016) 37 Comp Lab L \& Pol'y J 619.

34 Bee Davies, 'Joe Biden Welcomes YouTube's Top Influencers to the White House' (Resource, 11 January 2017) http://resourcemagonline.com/2017/01/joe-biden -welcomes-youtubes-top-influencers-to-the-white-house/73493/. 
ing content on policy discussions taking place between the country's elected officials. ${ }^{35}$ While the right to free speech may be protecting the online opinions of influencers, once they are sponsored to promote political messages or have their own political agendas, many ethical and legal questions will be raised: Should it be permitted for politicians to use AdSense to monetize their videos on YouTube? If so, would this money count as a contribution to their political campaigns? Currently, Social Blade projects the earnings of Kataguiri's channel to a maximum of $\pm € 120,000$ per year. Should there be a limit to such earnings, or any special reporting duties? What about influencers who promote politicians or political parties for money? What kind of disclosures based on electoral law should influencers be subjected to?

The study of the regulation of social media influencers spans across a wide range of legal fields: it is a modern topic that involves almost every single field of law and asks us to rethink once again the distinction between peers and professionals, commercial speech and political speech, advertisement and opinion, reality and fiction. It also asks us to discuss the role of the digital intermediaries that turn regular individuals into influencers, how they use obscure algorithms to promote their content, how much they profit from it, and whether their role in content moderation should be revisited. Influencers are more and more vested in 'visibility games' on social media, ${ }^{36}$ namely they try to interpret how a platform's algorithms work, in a such a way that they can use the platform rules to their advantage and optimize the reach of their content. For instance, YouTube's most recent content moderation policies automatically demonetize videos that include profane or sensitive words, such as 'Satan' or 'Nazi'. ${ }^{37}$ Creators manage to game the automated moderation system by simply censoring them, and instead displaying them in writing within the video (e.g., in subtitles). Yet there are certain measures taken by social media platforms that influencers simply cannot avoid. This was the example of Jessy Taylor, a 21-year old influencer from Florida, whose Instagram account was allegedly reported for inappropriate content with such consistency, that Instagram decided to unilaterally remove her account for violating its terms

\footnotetext{
35 Kim Kataguiri, YouTube channel (YouTube, 2019) https://www.youtube.com/ user/Tharryify.

${ }^{36}$ Kelley Cotter, 'Playing the Visibility Game: How Digital Influencers and Algorithms Negotiate Influence on Instagram' (2019) 21(4) New Media \& Society 895.

37 Todd Spangler, 'YouTube Explains Which Profanities and "Inappropriate Language” Are Not OK for Ad-Supported Videos' (Variety, 14 January 2019) https:// variety.com/2019/digital/news/youtube-profanity-ad-supported-video-demonetized $-1203107619 /$.
} 
of service. ${ }^{38}$ As platforms intensify their content moderation functions, it becomes increasingly unclear how they use their discretion in applying sanctions to non-compliant users. This raises questions relating to the legitimacy of private sanctions, but also relating to access to justice, as influencers deprived of their account data, and completely unaware of the black-box algorithms used by digital platforms, can hardly prove that they themselves were victims of for example breach of contract by the social media platforms.

With so many more issues than just advertising, it is therefore essential to tackle the wider theme of social media influencers to understand some of the practices used by them, which may affect current and future generations, industries and overall societies. Moreover, it is equally important to analyse this phenomenon not only by interpreting the law, but by showcasing the interdisciplinary potential of the topic. Therefore, this book has brought together a number of different disciplines that have been studying influencer marketing from various perspectives and that rarely converse with each other: law, communication sciences, ethics, business, and philosophy can all help shed light on the socio-legal and economic complexity of the activity of social media influencers.

\section{THE BOOK}

This book delves into the regulatory challenges resulting from the activity of social media influencers. It fills an important gap in the academic literature by providing an interdisciplinary analysis of a phenomenon with growing societal relevance. Given their large audiences (hundreds of thousands, if not millions in several cases), influencers are very effective not only at creating online engagement for the companies that employ their services, but also at manipulating their followers' opinions and transactional behaviour, as the latter do not always distinguish between genuine and sponsored marketing advice. Although advertising regulations include endorsements made on Instagram or YouTube by 'prosumers', influencers appear to disregard these regulatory limits and national regulators have experienced difficulties in safeguarding their enforcement. In this context, average social media users are at an ever-greater risk of falling prey to inconspicuous commercial interests.

On the one hand, empowering users to start their own channels or accounts and be able to gather revenue as an alternative to a classical job sounds promis-

38 Chelsea Ritschel, 'Instagram Influencer Whose Account Was Deleted Said She Called the Police Because It Felt Like "Murder"' (The Independent, 12 April 2019) https:/www.independent.co.uk/life-style/instagram-influencer-jessy-taylor-cry-call -police-job-a8868016.html. 
ing: there are no market entry requirements, it provides the much-coveted millennial work flexibility, and can be a good alternative if job prospects are dire. On the other hand, influencer marketing raises fundamental legal and moral questions that range from the disclosure of sponsorship deals to the obscurity of business models, the purchase of 'fake followers' or the legal consequences of disconnecting an influencer from a social media platform, depriving them of their main source of income. These legal issues also refer to the protection of their audience: What happens with influencer content which entails health risks, such as the promotion of cosmetic surgery or medical products? In addition, given that impressionable children between seven and 15 represent a significant audience on social media, should special regulations be drafted to ensure that they benefit from any additional protections? And if so, can we draw on existing regulations applicable to traditional media (e.g., the rules that in some countries prohibit the advertising of non-child friendly products or food with high sugar content at certain times of the day)?

This edited volume explores the potential and challenges posed by the activities of social media influencers, interrogates the limitations of the current regulatory framework applicable to influencer marketing, and examines how this framework can be adapted to take into account both consumer and commercial interests.

The contributions bring together insights from media studies, law, communication science and empirical legal studies, dealing with themes such as social media, influencer marketing, free speech, gig work, platform governance and consumer protection. Drawing on existing literature as well as original empirical findings, this book seeks to:

(i) understand when social media users should be identified as influencers and explain the legal implications thereof;

(ii) provide a historical overview of the significance of influencer marketing and the meaning of social media in the reshaping of this new form of advertising and engagement with the public;

(iii) analyse the phenomenon of social media influence in light of the freedom of expression and the right to publicity;

(iv) clarify how social media influencers contribute to the development of new forms of consumer empowerment and creative work;

(v) analyse what unfair trade and consumer protection issues arise from their activities;

(vi) clarify existing practices in the service supply chain and the distribution of legal responsibilities therein;

(vii) discuss the liability of online platforms for complying with existing legal frameworks. 
This book addresses the rising concerns brought about by influencer marketing while balancing them against its economic benefits and innovation potential.

Part I addresses social media, free speech and public interest. Influencer marketing is based on balancing the expression of speech in a commercial and non-commercial context with the public interests they may touch upon.

In Chapter 2, Ernesto Apa and Oreste Pollicino address constitutional law questions related to the judicial protection of free speech on the Internet, particularly when this speech belongs to social media influencers. Their comparative analysis shows how free speech is regulated in different jurisdictions and how this may impact social media influencers who despite being based in one jurisdiction, serve a growing global community of followers.

Chapter 3, authored by Madeleine de Cock Buning, reveals a much-needed insider perspective of regulatory processes - both at Dutch and European level - focusing on the regulation of media and advertising. The chapter takes a regulatory perspective on transparency in commercial communication by social media influencers with a focus on the new European Audiovisual Media Service Directive 2018 (AVMS Directive 2018) in the context of existing rather successful (self-)regulatory models in the Netherlands.

Isabel Ebert and Dana Sindermann dedicate Chapter 4 to the discussion of the ethical implications of influencer marketing from two perspectives, combining two distinct lenses of analysis that can be subsumed under business ethics. On the one hand this chapter discusses the relationship between the influencer and the individual company that the influencer endorses products for, arguing this approach is disguised consumer manipulation. On the other hand, it depicts the relevance of the Business and Human Rights approach for influencer marketing.

Chapter 5, written by Simone van der Hof, Valerie Verdoodt and Mark Leiser, addresses the economic activities of child influencers which can be interpreted as a form of commercial exploitation, covered by international child rights law as well as national standards. This chapter raises interesting questions about the need for additional regulatory frameworks to protect child influencers, since a routine aspect of adolescence in the digital era is participating in and consuming media produced by online communities of friends and strangers alike.

Part II looks into influencer marketing as work, given young people's infatuation with this activity for the purpose of generating personal income, but also in the face of new labour challenges that arise out of current business models.

In Chapter 6, Marijke De Veirman, Steffi De Jans, Elisabeth Van den Abeele and Liselot Hudders shed light on how teenage influencers perceive the process of becoming an influencer and the impact they have on peers with their influencer activities on social media. In-depth interviews with 12 Belgian 
teenage influencers show that they maintain multiple social media accounts, with Instagram and TikTok being the most important ones.

Chapter 7 by Gemma Newlands and Christian Fieseler deconstructs the notion of influencer marketing as an achievable career goal, looking at how influencer marketing is a hybrid phenomenon, merging the advertising logics of traditional celebrity endorsements with social media's preoccupation with 'authentic' and self-generated consumer content.

David Mangan's contribution, Chapter 8, predominantly examines how social media influencers reveal information technology's impact on labour law. The distinction between an independent commercial entity and a worker or employee (as a category variously captured by employment regulation) remains contested terrain, and the chapter shows how existing frameworks fare in the context of the new challenges posed by social media influencers.

To emphasize the transactional nature of influencer marketing, Part III focuses on consumer disclosures and contract law.

Chapter 9, written by Catalina Goanta and Isabelle Wildhaber, aims to unveil a side of influencer marketing that remains underexplored: the control of social media content through private law mechanisms. As the influencer market is inherently transactional, it is important to understand what business practices define this industry from the perspective of how legal risks are divided among contracting parties in the supply chain of influencer marketing.

In Chapter 10, Rossana Ducato critically reconstructs the legal framework applicable to the phenomenon of influencer marketing with particular attention to the information obligations of influencers and social media platforms. The chapter explores potential tensions arising in the unfair commercial practices, e-commerce and media law frameworks and offers a comparative overview of the first decisions issued in this field.

While the first three parts of the book focus on tackling substantive issues arising out of influencer marketing, Part IV addresses social media and empirical research design in order to illustrate problems and solutions which may be taken into account when conducting empirical research on social media matters surrounding influencers.

In Chapter 11, Monika Leszczyńska and Gijs van Dijck discuss empirical research on social media influencers as a way to extract useful insights about influencer marketing. Importantly, this research is conducted using different data collection methods and research designs. The goal of Chapter 10 is to enhance drawing proper conclusions from this variety of empirical research as well as understanding the potential but also the limitations of it.

Felix Pflücke's Chapter 12 examines the consumer protection rules applicable to influencer marketing, and empirically assesses whether five selected social media platforms comply with the legal obligations. The chapter further reflects on the role of platforms in the regulatory framework related to social 
media influencers, from a perspective of compliance with top-down regulation, but also raising questions about self-regulation.

While this book does not claim to address all the legal and ethical problems of influencer marketing, it sets the scene for a growing field of interdisciplinary research. Influencer marketing and WOM precede social media but they feed off the same ingredients: trust based on the credibility of advertisers/ endorsers, relatability, low-threshold information, and entertainment. Two central features distinguish modern influencer marketing from traditional marketing techniques: first, social media influencers often monetize appearances (of expertise, influence, authenticity) rather than real knowledge; second, influencers serve an audience that may not always have the digital literacy to distinguish what it is real from what it is not. Law plays a key role in this context as a guardian against deception, defamation, professional malpractices and lack of accountability. 